\title{
The Use of Fricke Dosimetry for Low Energy X-Rays
}

\author{
Carlos de Austerlitz ${ }^{*}$, Viviane Souza ${ }^{1}$, Heldio Pereira Villar ${ }^{1,2}$ and Aloisio Cordilha ${ }^{3}$ \\ Centro Regional de Ciências Nucleares; Rua Cônego Barata, 999; Tamarineira; 52110-120; auster@elogica.com; \\ vlsouza@cnen.gov.br; Recife - PE - Brasil. ${ }^{2}$ Escola Politécnica de Pernambuco; Praça do Internacional, 455; \\ 50750-470; hpvillar@aol.com; Recife - PE - Brasil. ${ }^{3}$ Instituto de Radioproteção e Dosimetria; Av. Salvador Allende \\ s/n; Recreio dos Bandeirantes; 22780-160; aloisio@ird.gov.br; Rio de Janeiro - RJ - Brasil
}

\begin{abstract}
The performance of four X-ray qualities generated in a Pantak X-ray machine operating at 30-100 kV was determined with a parallel-plate ionization chamber and a Fricke dosimeter. X-ray qualities used were those recommended by Deutsch Internationale Normung DIN 6809 and dose measurements were carried out with Plexiglas $^{\circledR}$ simulators. Results have shown that the Fricke dosimeter can be used not only for soft X-ray dosimetry, but also for the maintenance of low-energy measuring systems' calibration factor.
\end{abstract}

Key words: Radiation dosimetry, soft X-rays, Fricke dosimeter

\section{INTRODUCTION}

Cobalt-60 irradiators, linear accelerators and soft $\mathrm{X}$-ray machines have been routinely used for the treatment of malignant tumors in hospitals worldwide. The perspective of healing malignant tumors is dependent on the magnitude of the radiation dose applied during therapy. In this regard, underdosage may jeopardize the tumor control probability, They are difficult to discover, may be only detected after a relatively long time and, therefore may involve a large number of patients. On the other hand, too high radiation doses, despite their high probability of success in the killing of a tumor, increase the frequency of late effects in treated patients [1].

In general, optimum radiation dose levels for radiotherapy vary with the type of tumor and radiation source specifications [2]. On the basis of technical reports of inspections carried out by CNEN, the green light is given to clinics and hospitals where deviations between actual doses applied to patients and those measured during inspections are of $3 \%$ or less, the same value as those published in the scientific literature [3].

Although the $3 \%$ uncertainty can be seen as quite adequate for radiotherapy procedures, CNEN's inspections are not extended for soft X-ray machines, so that their control is left to the clinics' physicians. Based on CNEN's recommendations and the assumption that the measuring system being used shows no changes in response/sensitivity during the 12 months following its calibration [4], this control is based on dosimetry measurements carried out with a parallel-plate ionization chamber.

Therefore there is no national intercomparison program for therapeutic X-ray machines. On the other hand, the transportation of measuring systems and standards in a continental country such as Brazil and the costs incurred must be appreciated.

\footnotetext{
* Author for correspondence
} 
The present paper shows how low-energy Fricke dosimetry can be used for the quality control of soft X-ray machines and how the calibration factor of measuring systems used for soft X-ray dosimetry can be maintained.

\section{MATERIALS AND METHODS}

A 160-kV Pantak X-ray machine was used for the irradiation of a reference measuring system and the Fricke dosimeter. The high voltages applied to the X-ray tube were determined with an Eurisys (HP)Ge X-ray spectrometer for the radiation qualities shown in Table 1, as specified by the Deutsches Institut für Normung [5]. Half-value layers were determined with $99.99 \%$ pure aluminum filters, and the mean energy of the radiation beams was derived from the mean averages for the radiation qualities by the Deutsches Institut für Normung [6].

A measuring system comprising an NE model 2670-A electrometer and a PTW model 2532/3C ionization chamber (England), designed to measuring absorbed due to $\mathrm{x}$-rays beams generated by tube potential ranged from 10 to $100 \mathrm{kV}$, was used for dosimetry purposes. Irradiated Fricke solution's optical density was measured in a quartz cuvette (1-cm path length) with a UV-VIS (150 $800 \mathrm{~nm})$ Beckman Coulter DU 640 spectrophotometer (EUA), and the temperature was measured with Eutechnics digital thermometer Moodel 4400 (EUA). The Fricke solution itself was synthesized with $0.392 \mathrm{~g}$ of hexahydrated ferrous-ammonium sulfate ammonium P. A. $\left(10^{-3}\right.$, MERCK), $0.060 \mathrm{~g}$ of sodium chloride P. A. $\left(10^{-3}\right.$, MERCK) and $22 \mathrm{~mL}$ of concentrated sulfuric acid P. A. (MERCK) diluted in Milli-Q (18.2 M $\Omega . c m)$ water in a 1,000-mL volumetric balloon (corresponding to a total mass of $1,022.7 \mathrm{~g}$ ). The water-acid system was previously irradiated at 10
Gy to eliminate impurities [7]. Once the solution was ready, $3.5-\mathrm{mL}$ aliquots were transferred to several 6-mL sterilized "vacutainer" plastic vials. The experimental setup for irradiation of the ionization chamber and the Fricke solution is shown in Fig. 1. The ionization chamber and the plastic vials were placed on the surface of a Plexiglas ${ }^{\circledR}$ simulator with $110 \mathrm{~mm}$ x $110 \mathrm{~mm} \times 80$ $\mathrm{mm}$. Finally, both measuring systems were irradiated with the radiation qualities presented in Table 1.

The ionization chamber was positioned on the simulator with the center of the entrance window (sensitive volume) perpendicular to the radiation beam's central axis. The dose absorbed in water, $\mathrm{D}_{\mathrm{W}}$, in grays (Gy) was obtained from the average of five readings, $\mathrm{M}_{\mathrm{P}}$, through equation. (1).

$\mathrm{D}_{\mathrm{W}}=\mathrm{N}_{\mathrm{D}} * \mathrm{M}_{\mathrm{P}} * \mathrm{~K}_{\rho}$

Where,

$\mathrm{N}_{\mathrm{D}}$ - calibration factor in terms of dose absorbed in water.

$M_{P}$ - reading obtained with the measuring system in its own units when the ionization chamber is in the simulator.

$\mathrm{K}_{\mathrm{p}}-$ correction factor for air density relative to reference conditions $\left(20.00{ }^{\circ} \mathrm{C}\right.$ e $\left.101.33 \mathrm{kPa}\right)$, as calculated by equation (2).

$$
k_{T P}=\left(\frac{273,15+T}{293,15}\right)\left(\frac{101,33}{P}\right)
$$

where $\mathrm{T}$ and $\mathrm{P}$ are the temperature in ${ }^{\circ} \mathrm{C}$ and pressure in $\mathrm{kPa}$, respectively, in the vicinities of the chamber during the measuring procedure.

Fig. 1. Irradiation set up for ionization chamber (a) and Fricke solution (b) 

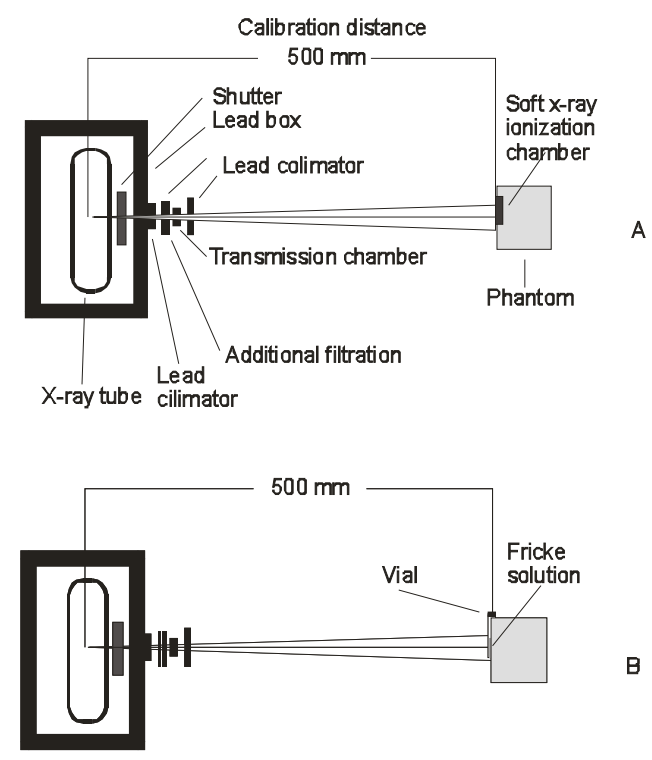

Figure 1 - ionization chamber irradiation (A) and fricke dosimeter irradiation (B)

Table 1 - X-ray qualities recommended by the DIN 6809 [6].

\begin{tabular}{cccc}
\hline High voltage $(\mathbf{k V})$ & $\begin{array}{c}\text { Additional filtration } \\
(\mathbf{m m} \text { Al) }\end{array}$ & $\begin{array}{c}\text { Half-value layer } \\
(\mathbf{m m ~ A l})\end{array}$ & Mean energy (keV) \\
\hline 30 & 0.447 & 0.370 & 19.7 \\
50 & 0.894 & 1.021 & 29.4 \\
70 & 3.965 & 3.110 & 42.1 \\
100 & 4.164 & 4.520 & 52.2 \\
\hline
\end{tabular}

The polyethylene tubes containing the Fricke solution were half-embedded in the Plexiglas ${ }^{\circledR}$ simulator at a distance of $500 \mathrm{~mm}$ relative to the Xray tube focal point, as shown in Fig. 1b. The geometric center of the solution volume was taken as the reference point. The Fricke dosimeters were irradiated with a 50-mm wide circular field and a radiation dose of $40.0 \mathrm{~Gy}$, as determined with the ionization chamber. Doses obtained with the Fricke solution were calculated in accordance with International Atomic Energy Agency recommendations, IAEA TRS 178 [8], as specified by equation (3) [7],[8].

$D_{W}=\frac{\Delta O D \cdot N_{A}}{G\left(F_{e}^{3+}\right) \cdot \varepsilon\left(t^{o} C\right) \cdot d \cdot \rho \cdot f_{1} \cdot f_{2}} \quad[G y]$

In this equation,

$$
\begin{aligned}
& f_{1}=1+0,0069\left(T_{l}-25\right) \\
& f_{2}=1+0,0012\left(T_{i}-25\right)
\end{aligned}
$$

and $\Delta \mathrm{OD}$ - change in the irradiated solution's optical density relative to the non-irradiated solution at a wavelength of $304 \mathrm{~nm}$ (absorption peak of $\mathrm{Fe}^{3+}$ ).

$\mathrm{N}_{\mathrm{A}}$ - Avogadro's number

$\mathrm{G}\left(\mathrm{Fe}^{3+}\right)$ - chemical yield for the irradiation energy

$\varepsilon$ - molar extinction coefficient

d - optical pathway

$\rho$ - solution density

$\mathrm{T}_{\mathrm{i}}$ - solution temperature during irradiation $\left({ }^{\circ} \mathrm{C}\right)$

$\mathrm{T}_{1}-$ solution temperature during measurement $\left({ }^{\circ} \mathrm{C}\right)$.

In the present work values of $218.7 \mathrm{~m}^{2} \mathrm{~mol}^{-1}$ for the molar extinction coefficient of $\mathrm{Fe}^{3+}$ at $25^{\circ} \mathrm{C}$ [9] and of $1,022.7 \mathrm{~kg} \cdot \mathrm{m}^{-3}$ for the solution density [7] were assumed. Moreover, the cuvette utilized in the spectrophotometer had an optical pathway of 10 $\mathrm{mm}$ and factors $\mathrm{f}_{1}$ and $\mathrm{f}_{2}$ are those described by $\mathrm{A}$. Olszanski et al [7].

Finally the values for the chemical yield $\mathrm{G}\left(\mathrm{Fe}^{3+}\right)$ are those recommended by ICRU Report 17 for dosimetry procedures for radiations generated with 
high voltages between 5 and $150 \mathrm{kV}$ [10], shown in Figure 2. In this figure, the mean values of $\mathrm{G}\left(\mathrm{Fe}^{3+}\right)$ evaluated by several authors published by ICRU Report 17 (Table 2) were fitted to specify the radiation qualities used in the present work as shown in Fig. 2.

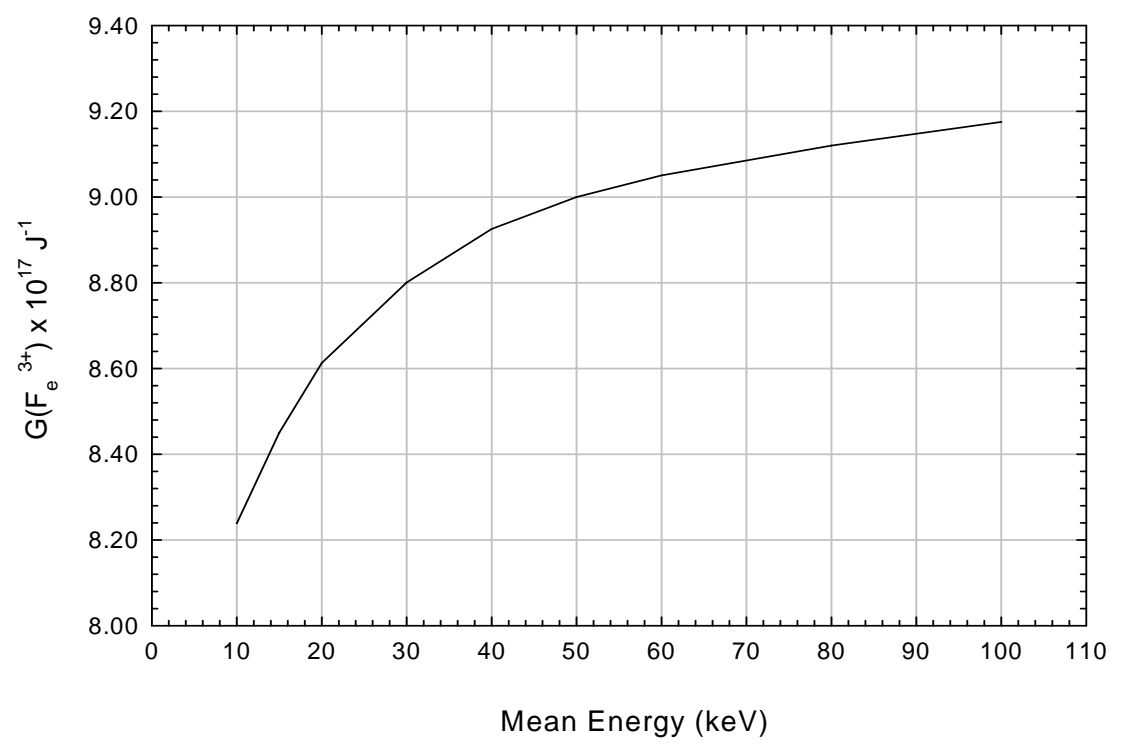

Figure 2 - Chemical yield $\mathrm{G}\left(\mathrm{Fe}^{3+}\right)$. Fitted data taken from the ICRU Report 17[10].

Table 2 - Chemical yield values used to calculate absorbed doses.

\begin{tabular}{cc}
\hline Potencial $(\mathbf{k V})$ & $\mathbf{G}\left(\mathbf{F e}^{3+}\right) \mathbf{x 1 0 ^ { 1 7 } \mathbf { J } ^ { - 1 }}$ \\
\hline 30 & 8.61 \\
50 & 8.80 \\
70 & 8.93 \\
100 & 8.99 \\
\hline
\end{tabular}

For instance, for the radiation quality produced at $70 \mathrm{kV}$, the absorbed dose may be calculated by equation. (6):

$$
D_{W 70 k V}=(\Delta O D x 301,5) / f_{1} f_{2} \quad[G y]
$$

\section{RESULTS AND DISCUSSION}

Figure 3 shows doses absorbed in water evaluated with the ionization chamber and the Fricke dosimeter for the radiation qualities presented in Table 1.

No investigation was carried out to determine the total uncertainty in the determination of the dose with the ionization chamber or the Fricke dosimeter. Nevertheless, based on the chamber's calibration factor uncertainty $(3.5 \%)$ and the Fricke dosimeter's long term stability (3\%), and by taking the total uncertainty as the square root of the sum of the squares of each individual uncertainty, it is expected that dose values determined by both measuring systems should not deviate by more than $4.6 \%$. 


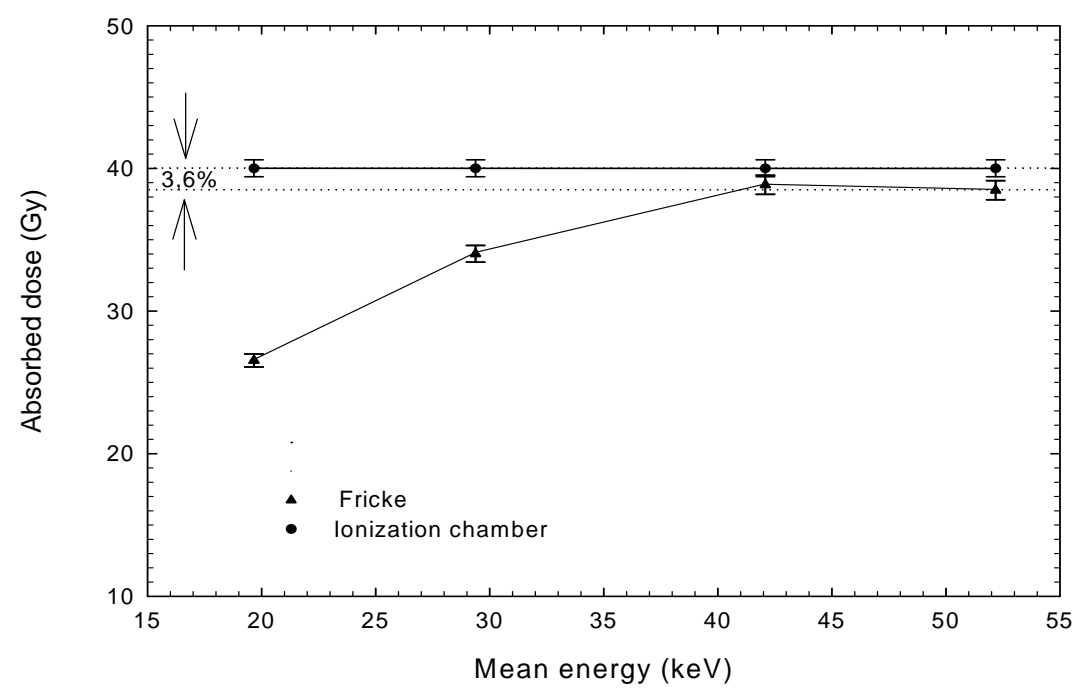

Figure 3 - Fricke dosimeter response as a function of radiation energy for $40 \mathrm{~Gy}$.

This value is very conservative when compared with the uncertainty evaluated by Souza $[11,12]$ (3.5\%) in the determination of absorbed dose of soft $x$-rays equipments using the same spectrophotometer as the one used in this work.

For radiation qualities corresponding to 50 and 30 $\mathrm{kV}(29.4-19.7 \mathrm{keV})$ doses determined with the Fricke dosimeter are lower by 18 and $51 \%$, respectively, than those obtained with the ionization chamber. This can be explained by the beam attenuation in the vial's walls, as well as to the dose gradient due to the Fricke solution itself. Preliminary Monte Carlo modeling using Pire ${ }^{\circledR}$ and polyethylene Fricke's vials has shown that the attenuation suffered by the radiation beam when it interacts to the solution vial's walls and solution's depends on the vial material and thickness as well as the volume of the Fricke solution inside the vial. Such data are not yet published because further experiment is going on by using plastic phantoms made of a thinner layer of Polyethylene filled with water to evaluate absorbed doses with ionization chambers and Fricke dosimeter, as suggested by Austerlitz [13].

Although the Fricke dosimeter has been used to measure absorbed dose in an absolute way, the measurements performed with the PTW model 2532/3C ionization chamber were necessary to show the energy's threshold in which the Fricke dosimeter can be used based on the conventional formalism of absorbed dose calculation.

The $70-\mathrm{kV}$ radiation quality was taken as a standard for the maintenance of CRCN's calibration factors for the following reasons: (a) it is in the energy range where the Fricke dosimeter response shows a relatively low energy dependence, and (b) this quality presents a halfvalue layer similar to that employed by Brazil's National Laboratory for Ionizing Radiation Dosimetry, that adopts reference qualities for the calibration of Bureau International des Poids et Mesures, Sèvres ionization chambers [14].

Therapeutic X-ray machines operate with high dose rates, which enable the utilization of Fricke dosimetry to be applied to them. Moreover, the Fricke dosimeter components are small enough to be sent by mail to clinics and hospitals all over the country. The adoption of this procedure would ensure that a comprehensive dose control in radiotherapy units be achieved at a much lower cost than that associated with CNEN's conventional inspections.

The dependence of the Fricke dosimeter with the energy of the $x$-ray beam in the range of 30 to 50 $\mathrm{kV}$ tube potential can be used to perform quality control of half-value layers of soft x-ray 
machines. This can be done by measuring the output of an X-ray machine with Fricke dosimeter at two different kilovoltages, e.g., at $100 \mathrm{kV}$ and $30 \mathrm{kV}$, and calculating the absorbed dose by using the predicted values of the HVLs for such equipment to correct the Fricke dosimeter energy dependence showed in Figure 3. If there are an agreement between predicted and measured output values for both kilovoltages, the predicted value of the HVL for the lowest energy x-rays is correct. If only the output values for $100 \mathrm{kV}$ agree, the HVLs for such machine shoud be reevaluated. Pilot measurements performed with three different types of therapeutic soft X-rays equipment in northeastern Brazilian's hospitals has shown the feasibility of the Fricke system used in this work. Additionally, the uncertainty in the determination of the absorbed dose does not exceed $3 \%$ when the values of the optical densities is higher than 0.14 [11].

\section{CONCLUSIONS}

From what has been presented so far, the following conclusions may be drawn:

For x-ray produced by tube potential ranged from 70 to $100 \mathrm{kV}(42 \mathrm{keV}$ to $52 \mathrm{keV})$ the Fricke dosimeter can be employed for the quality control of soft X-ray machines for on site measurement combined with postal delivered.

For energies below $42 \mathrm{keV}$ the attenuation of the $\mathrm{X}$-ray beam caused by the vial wall and the Fricke solution has to be considered in the traditional formalism to calculate absorbed dose with the Fricke dosimeter. However, the dependence of the Fricke dosimeter with the energy of the X-ray beam can be used to perform quality control of half-value layers. This can be done by measuring and comparing the output values of an X-ray machine with Fricke dosimeter and an ionization chamber at two different kilovoltages.

For the 42 to $52 \mathrm{keV}$ energy range Fricke dosimetry can be employed for the maintenance of calibration factors from measuring assemblies used in the dosimetry of soft X-ray machines.

\section{RESUMO}

Neste trabalho, o dosímetro Fricke foi utilizado para verificação dos rendimentos de quatro qualidades de radiação produzidas por um aparelho de raios-X Pantak de $160 \mathrm{kV}$ com potenciais entre 30 e $100 \mathrm{kV}$. Para tanto, foram utilizadas as qualidades de radiação recomendadas pela "Deutsh Internationale Normung" DIN 6809. As medidas foram realizadas em simuladores de plexiglas. Os resultados obtidos demonstraram que o dosímetro Fricke pode ser utilizado não apenas para a dosimetria desses equipamentos, mas também, para a manutenção do fator de calibração de sistemas de medidas para baixas energias.

\section{REFERENCES}

[1] ACS American Cancer Society "Clinical Oncology (1984), A Multidisciplinary Approach”, Sixth Edition, American Cancer Society, New York, USA.

[2] IAEA TRS 110 International Atomic Energy Agency (1970), "Manuall of Dosimetry in Radiotherapy", TRS 110, IAEA Publication, Viena.

[3] krieger T. And Sauer O., (2005) "Monte Carloversus pencil-beam/collapsed-cone-dose calculation in a heterogeneous multi-layer phantom, Phy. Med. Biol. 50, 859-868.

[4] Comissão Nacional de Energia Nuclear (1973), "Normas Básicas de Proteção Radiológica, Diário Oficial, Nr. 180, Seção I, Parte II-6.

[5] DIN 6809 (1998) “German Standard, Application of $\mathrm{X}$-rays with Tube Voltage between 10 and 100 $\mathrm{kV}$ in Radiotherapy and soft Tissue Diagnostics". DIN 6809, Part 4, Deutsches Institut für Normung, Berlin.

[6] Deutsches Institut für Normung (1984) "Dosimeter mit Ionisationskammern für Photonen- und Elektronenstrahlung zur Verwendung in der Strahlentherapie; Regeln für dir Herstellung”, Berlin, DIN 6817.

[7] IRS (2002), A. Olszanski, A., Klassen, N. V., Ross C. K., and Shortt, K. R., "The IRS Fricke Dosimetry System", Ionizing Radiation Standards, Institute for National Measurement Standards, National Research Council, PIRS0815, Ottawa, Ontario.

[8] International Atomic Energy Agency (1977) "Manual of Food Irradiation Dosimetry", TRS 178, IAEA, Vienna.

[9] Attix, F.H. (1986) "Introduction to Radiological Physics and Radiation Dosimetry", WileyIntersciende Publication, USA.

[10] International Commission on Radiation Units and Measurements (1970) "Radiation dosimetry: XRays Generated at Potententials of 5 to $150 \mathrm{kV}$ ", ICRU Publications, Washington .C., USA. 
[11] Souza, V. L. B. And Austerlitz, C. (2005), "Determinação de $\mathrm{NH}_{4} \mathrm{Fe}\left(\mathrm{SO}_{4}\right)_{2}$ em solução Fricke com o espectrofotômetro beckman DU 640", 1o. Congresso Brasileiro de Proteção Radiológica, Hotel Glória, Rio de Janeiro, Brazil

[12] Souza, V. L. B.; Austerlitz, C. e Benevides, C., (2005) A. "O Sistema de Dosimetria Fricke do CRCN/CNEN", X Congresso Brasileiro de Física Médica, Salvador, BA, Brazil.

[13] Austerlitz, C., Villar, H.P., and Santos, M.A.P., (2004), "Influence of field size on a PTW type 23342 plane-parallel ionization chamber's response", Med. Phy., 31, 12, 3201-3205.

[14] Boutillon, M; Allisy-Roberts, P.J. \& Burns, D.T. (2001) "Measuring Conditions Used for the Calibration of Ionization Chambers at BIPM" Raport BIPM-01/04, Bureau International des Poids et Mesures, Sèvres.

Received: July 29, 2005; Revised: September 05, 2005; Accepted: November 22, 2005. 
PÁGINA

EM

BRANCO 